\title{
SHIP MANEUVERABILITY EXPERIMENTS ON OPEN WATER WITH RUDDER MODEL VARIATIONS: CASE STUDY OF SPB-XXOO
}

\author{
Rizka Arie Hutama | Wasis Dwi Aryawan* | Ericza Damaranda Sugita
}

Dept. of Naval Architecture, Institut Teknologi Sepuluh Nopember, Surabaya, Indonesia

\section{Correspondence}

*Wasis Dwi Aryawan, Dept. of Naval Architecture, Institut Teknologi Sepuluh Nopember, Surabaya, Indonesia. Email: aryawanwasis@gmail.com

\section{Present Address}

Gedung Teknik Perkapalan, Kampus ITS Sukolilo, Surabaya 60111, Indonesia

\begin{abstract}
Ship maneuverability is important to study because it affects safety. Moreover, if the ship operates in a narrow shipping lane, as experienced by SPUB that operated in Musi River. This research focuses on the experimental process of SPUB maneuvers in open water, especially for the turning circles' movement. The experiment was conducted using a prototype, model SPB-XXOO, which was equipped with components of the instrumentation system such as data logger and propulsion system. Both are integrated into the remote control and computer to perform control functions, calculations, data logging, and data transfer through the wireless communication system. The main controller of the propulsion system is an implanted program to deflect the rudder automatically. Three rudder models with variations in aspect ratios of 1.10, 1.65 , and 2.20, also two variations of the rudder angle; $30 \mathrm{o}$ and $35 \mathrm{o}$ are used to test the model. GPS does the data acquisition process for each experimental process. Based on the analysis of the rudder model's effect, it was found that a rudder with a large aspect ratio provides better performance than a lower aspect ratio. The average increase in the maneuver performance of the rudder with the smallest to the most significant aspect ratio is $17.345 \%$.
\end{abstract}

\section{KEYWORDS:}

Drone, GPS, Instrumentation, Open Water, Maneuver Experiment, Rudder Variation, Self-propelled Barge, Turning Circle

\section{1 | INTRODUCTION}

A barge is a vessel with a flat-bottomed hull or a large floating beam used to transport bulky goods. It also used to anticipate the tidal condition as done by floating docks ${ }^{11}$. With its body hull, the barge is suitable to be operated in Indonesia's waters, especially in Kalimantan and Sumatra, where many shipping lines are through river and canal. One of the SPB operated in the 


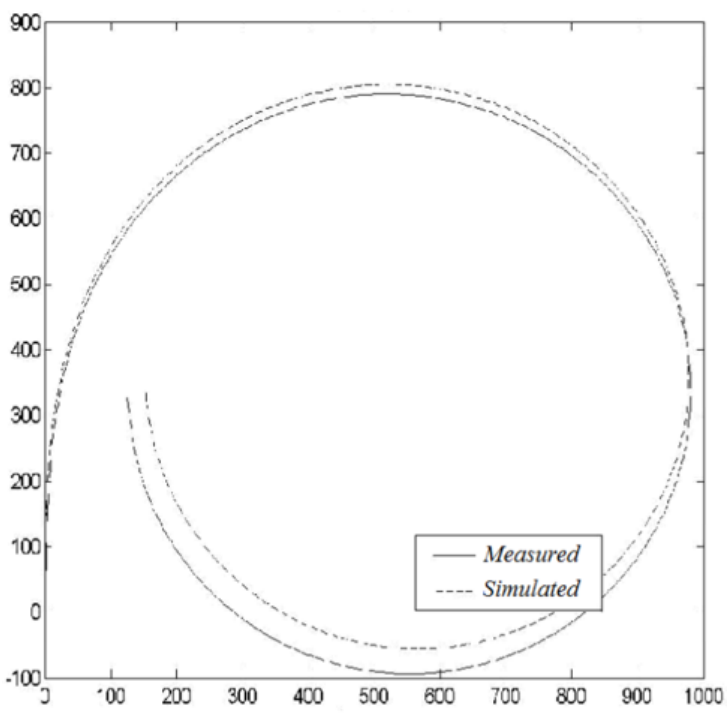

FIGURE 1 Graphs of experiment results of turning circle maneuvers for the original ship and model.

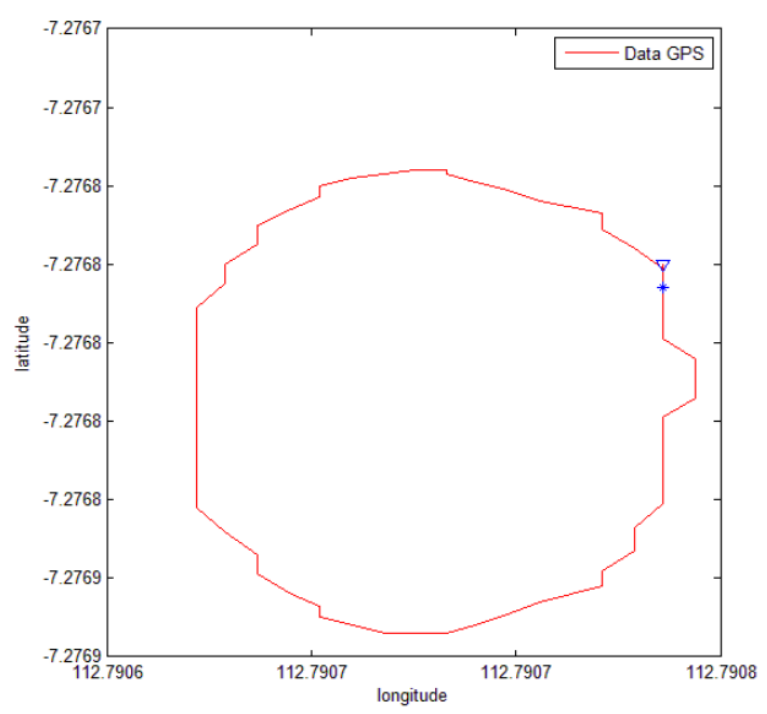

FIGURE 2 Mapping results of GPS coordinate data for turning circle maneuver $35^{\circ}$.

river area is Self-Propelled Urea Barge (SPUB) Pusri Indonesia I. Due to this condition, the maneuverability of SPUB needs to be considered because it is closely related to the safety of the ship.

Various methods for assessing vessel maneuverability have been carried out and published with their advantage and disadvantage. In this study, experiments will be conducted to assess the maneuverability of the SPUB. The experiments were carried out in open water using a scaled SPUB hull (without modification). This prototype then referred to as SPB-XXOO. Ship maneuvering models are the keys to the research of ship maneuverability, design of ship motion control system, and development of ship handling simulators ${ }^{[2]}$. The core of ship modeling is to estimate parameters of the ship model because many parameters cannot be measured physically with reasonable accuracy, especially in real-time ${ }^{[3}$.

Maneuverability is the ability to change direction (turn aside or turn back) in limited waters or open waters. A ship is referred to as having excellent maneuverability if she meets some criteria given by the International Maritime Organization (IMO) with reference to its length ${ }^{3}$. IMO through MSC Resolution 137 (76), was made a regulation regarding the maneuver criteria that must be owned by each ship through several types of testing. One of them is turning test (advance and tactical) at a rudder angle of $35^{\circ}$.

Experiments are carried out by intentionally giving a treatment or intervention (in the form of independent variables) to the research object to determine the effect of the treatment on the dependent variable (the variable understudy). This method gives real-time results and provides accurate test parameters, different from other methods that provide results based on the approach. The most critical constraint on this method is the accuracy of the model and instrumentation used. Thus, a system of identification is needed to improve the maneuver model's accuracy in ship design ${ }^{3}$.

A research conducted by Shi et al. [2], describes how to identify models using the Extended Kalman Filter (EKF). The experiments were carried out by turning the cycle and zigzag test in open water. The results of this test are compared with the original ship test results (sea trials). From both, it was found that the error obtained in the turning cycle test for the advance was $1.9 \%$, transfer $5 \%$, and the maneuver diameter $-0.2 \%$. This data is given in Figure 1 . The "Simulated" notation shows the experiment result of the model, and "Measured" shows the first ship test result from the sea trial.

Im and Seo ${ }^{[4]}$ also conduct Experiment-based research. The research object used is a 1:100 scaled model that focused on designing instrumentation systems such as computers, actuators, and sensors, including GPS and IMU. The experiment was carried out to investigate the model's performance, including the zigzag test and the turning circle. The ship produced a pretty good performance so that it can be used in subsequent studies, namely intelligent control on ships. 
An experiment to test the maneuverability of ship models in open water was carried out by Ridho ${ }^{[3}$. A three meters SIGMA extended class warship model was used as the object to analyze the maneuverability criteria for turning circle and zigzag. The model speed is 1 to $1.2 \mathrm{~m} / \mathrm{s}$. The rate of this model is obtained from the calculation of the kinematic equation is given in ITTC - Recommended Procedures and Guidelines section for Resistance Test (rev. 3) in the form of the Froud number (Fr) equation. The SIGMA extended class warship model is equipped with controller devices, Global Positioning Systems (GPS), Inertial Measurement Units (IMU), Wireless Local Area Networks (WLAN), speed logs, signal conditioners, propulsion systems, and servo. All components are integrated serially into the computer client, who has a function as the main controller of the model.

Figure 2 shows the plotting results of GPS coordinate data for turning circle maneuver $35^{\circ}$. The coordinates of the model location while do maneuver movement are connected using lines and shown on the red curve. The graph shows an gauche curve because the type of connecting line used is a polyline. The model coordinate data is sampled at 0.1 seconds by capturing signals from 4 satellites. The average speed of the model when on turning movement is $0.7 \mathrm{~m} / \mathrm{s}$. The results of this experiment, the advance distance is 9.953 meters, the transfer distance is 5.521 meters, and the tactical diameter is 9.939 meters ${ }^{33}$.

This research focuses on the maneuvering experiment (design and process) of the SPB-XXOO model on open water. The experiments were conducted using a prototype equipped with instrumentation system components and integrated data loggers. Some components listed include controller devices, a set of propulsion systems, ground control systems, and data logger systems. The data logging process is carried out by a GPS receiver for each experiment. Variations of the rudder model and variations of the rudder angle are also used to see the effect on the ship's maneuverability. After the experimental results were obtained, the analysis of the results was carried out with the formula Vincenty method. Formula Vincenty is a method used to get a distance between 2 coordinate points of known position ${ }^{3}$. This method is also used to find the location of objects by referring to the GPS coordinates in longitude and latitude format.

Some problems that will be solved in this research are creating an experimental design of ship maneuver performance on open water, conducting experiments with variations of rudder models and rudder angles, and analyzing the effect of rudder model replacement to the model maneuver performance. Based on these problems, a scenario for conducting this research is made, as given in the next section. The results of this maneuver experiment in open water are expected to be one method in testing the maneuverability of ships/models that can be used for educational and industrial purposes.

In determining the rudder model, the length of the chord and span must be considered because it gives a different effect on the lift and drag. The concept of wing theory can be used to analyze the performance of wings, rudder, spoilers, and other objects with foil-shaped pieces. A critical aspect of this concept is the aspect ratio. The aspect ratio (AR) is defined as the square of the span (s) divided by the area (A). For a wing with a rectangular shape, the aspect ratio is a comparison of the wingspan to the length of the chord (c) ${ }^{5}$. It can be formulated as follows:

$$
A R=\frac{s^{2}}{A}=\frac{s^{2}}{s \times c}=\frac{s}{c}
$$

The high aspect ratio has a lower drag and a slightly higher lift than the smaller aspect ratio ${ }^{[5}$. A glider is designed with a very high aspect ratio because the glide angle of a glider depends on the lift and the drag. The same thing applies to ships. Rudder with a high aspect ratio has lower drag and higher lift than the rudder with a small aspect ratio.

\section{2 | MATERIAL AND METHOD}

This research can be assumed to be an adventure. It starts with one main intention: determine ship maneuvers' performance using experimental methods in open water by applying different rudder models. In the experience, there must be activities carried out to achieve the goal and the research process. The stages of this research are divided into two. Stage-1 is dedicated to creating the design experiment, starting from the hull fabrication until the model trial process to ensure the instrumentation system runs well. Stage 2 is dedicated to conduct maneuver experiments and analyze the effect of the aspect ratio of the rudder on the maneuverability performance of the SPB-XXOO. 


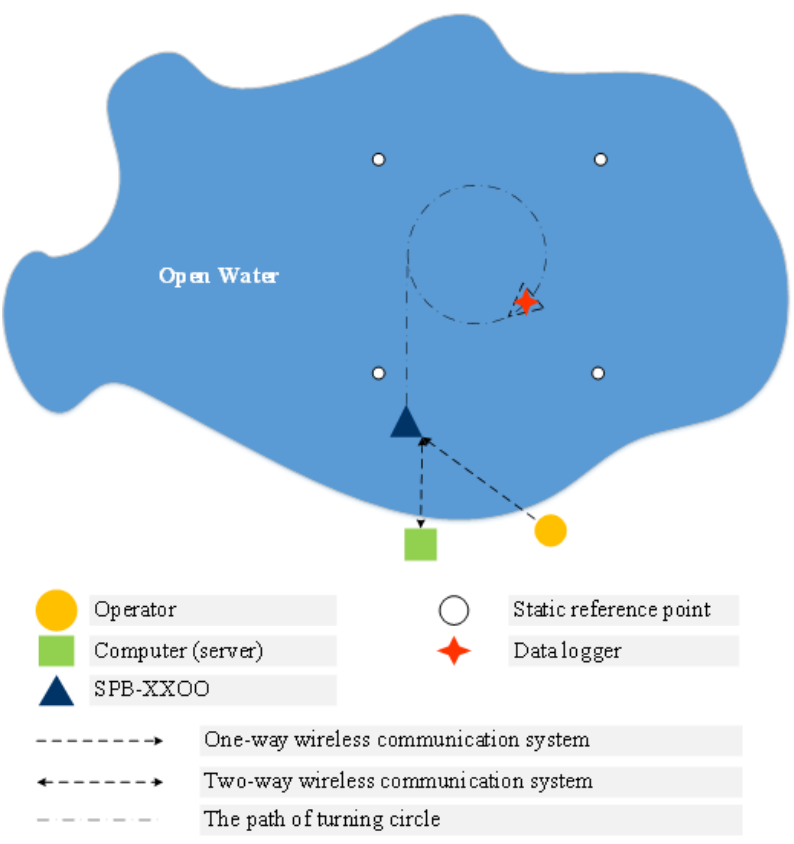

FIGURE 3 Illustration of the experimental process.

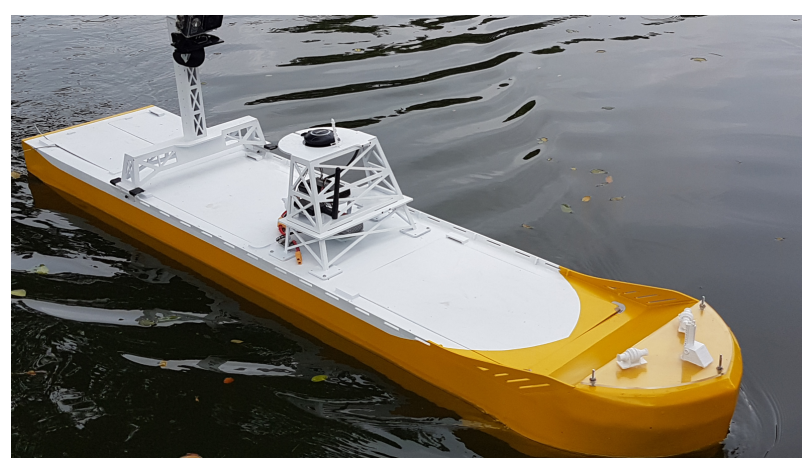

FIGURE 4 SPB-XXOO (prototype) model.

TABLE 1 Model particular dimensions.

\begin{tabular}{lrr}
\hline Parameter & Value & Unit \\
\hline LOA & 1.540 & meter \\
LPP & 1.502 & meter \\
LWL & 1.528 & meter \\
B & 0.303 & meter \\
H & 0.126 & meter \\
T & 0.062 & meter \\
Block Coeff. (CB) & 0.880 & - \\
LCB & 0.760 & meter \\
Displacement & 0.025 & meter3 \\
Static Trim (Trim) & 0 & meter \\
\hline
\end{tabular}

Maneuver analysis in open water is carried out by the system illustrated in Figure 3 This experiment technically and academically has the same concept as experiments in the laboratory. But the result might have a big difference with the actual outcome because of the external factors that interfere in the process of ship maneuvering movement and data logging processes, such as wind and waves. Internal factors, limited capabilities of the data logger component, may also be the most significant cause of errors. The results are given by experiments in open water only valid for a model/ship used for operations and with conditions during experiments. The same model might provide a different result if tested with different environmental conditions or various data logger components.

\section{1 | Model SPB-XXOO}

For the first stage of this study, the fabrication of SPB-XXOO was conducted based on the SPUB hull without any modification. The main dimensions and hydrodynamic characteristics of SPUB were collected from previous studies, that are listed in 64.86 . Based on these data, the process of fabricating a plywood model with a scale of 1:87 was carried out in the form of the SPBXXOO (prototype) model. The SPB-XXOO model is given in Figure 4 and its particular dimensions data presented in Table 1 
TABLE 2 Summary of instrumentation system components.

\begin{tabular}{lllr}
\hline No & Component & Category & Location \\
\hline 1 & Resource (battery) & All include & SPB-XXOO model \\
2 & Computer (server) & Communi-cation systems & Ground Control System (GCS) \\
3 & Radio control (transmitter) & Communi-cation systems & GCS \\
4 & Radio control (receiver) & Communi-cation systems & SPB-XXOO model \\
5 & Radio telemetry (ground) & Communi-cation systems & GCS \\
6 & Radio telemetry (air) & Communi-cation systems & SPB-XXOO model \\
7 & GPS & Data logger system & SPB-XXOO model \\
8 & Power Module & Data logger system & SPB-XXOO model \\
9 & Ardupilot Mega & Data logger system & SPB-XXOO model \\
10 & Regulator & Propulsion system & SPB-XXOO model \\
11 & Microcontroller Arduino UNO & Propulsion system & SPB-XXOO model \\
12 & Motor brushed DC & Propulsion system & SPB-XXOO model \\
13 & Motor servo & Propulsion system & SPB-XXOO model \\
14 & Motor driver & Propulsion system & SPB-XXOO model \\
15 & Propeller, Shaft, and Joint & Propulsion system & SPB-XXOO model \\
16 & Rudder set & Propulsion system & SPB-XXOO model \\
\hline
\end{tabular}

The speed of the SPB-XXOO is obtained from the scaling of SPUB's speed through kinematic equations. To express the magnitude of the speed of the model can use Froude's Number (Fr), where Fr is influenced by speed (v), gravity (g), and the length of the ship (L). The Froude Number is a unified number used to measure the resistance of an object moving through the water, and comparing objects of different sizes ${ }^{3}$. The Fr formula based on the literature of ITTC - Recommended Procedures and Guidelines section for Resistance Test (rev. 3) is stated in the following equations ${ }^{[9}$.

$$
\begin{gathered}
F r=\frac{V}{\sqrt{g \times L}} \\
F r_{S P B-X X O O}=F r_{S P U B}
\end{gathered}
$$

By obtaining SPUB speed (VSPUB), SPUB length (LSPUB), Model length (LSPB-XXOO), and gravity (g), the speed of the model (VSPB-XXOO) can be calculated. Constant speed in experiments is challenging to obtain because of the limitations of the research component. So in this study, the operational speed of 10-11 knots is used as a reference to get the speed of the model. calculation process in equations (1) and (2), it is found that the model speed is $0.5-0.6 \mathrm{~m} / \mathrm{s}$.

\section{2 | Instrumentation System}

The process of designing the system begins by estimating (calculating) the available space for the installation of machinery, communication, propulsion, and data logger components. Several components are placed outside the model: radio control/remote control (transmitter) and computer (server). The entire components, both hardware, and software, when assembled, will become a system called an instrumentation system. The summary of all components in this system is given in Table 2 In this study, the instrumentation system is developed to give input commands to propel the model according to the experimental scheme and records all model movement responses. The experimental work system (communication system) to analyze SPB-XXOO maneuvers is given in Figure 3 Based on its location, all components of the instrumentation system are grouped into 2; Ground Control System (GCS) and SPB-XXOO model. The components included in GCS are shown in green boxes, and the components included in the SPB-XXOO model are shown in blue boxes. Based on their function, these system components are grouped into 3: propulsion system, data logger system, and communication system. In Figure 3 each system is separated by a dashed line.

GCS is a system that developed to give input command to the model in the form of data, images, videos, or other formats. It also has a function as a data log server (library) of the maneuver experiments. Components included in this group are radio control (transmitter), radio telemetry, and computer (server). The computer (server) becomes the most critical component in this system because it functions as a data log server (library). To carry out its functions, the computer should contain some supporting software, such as: 


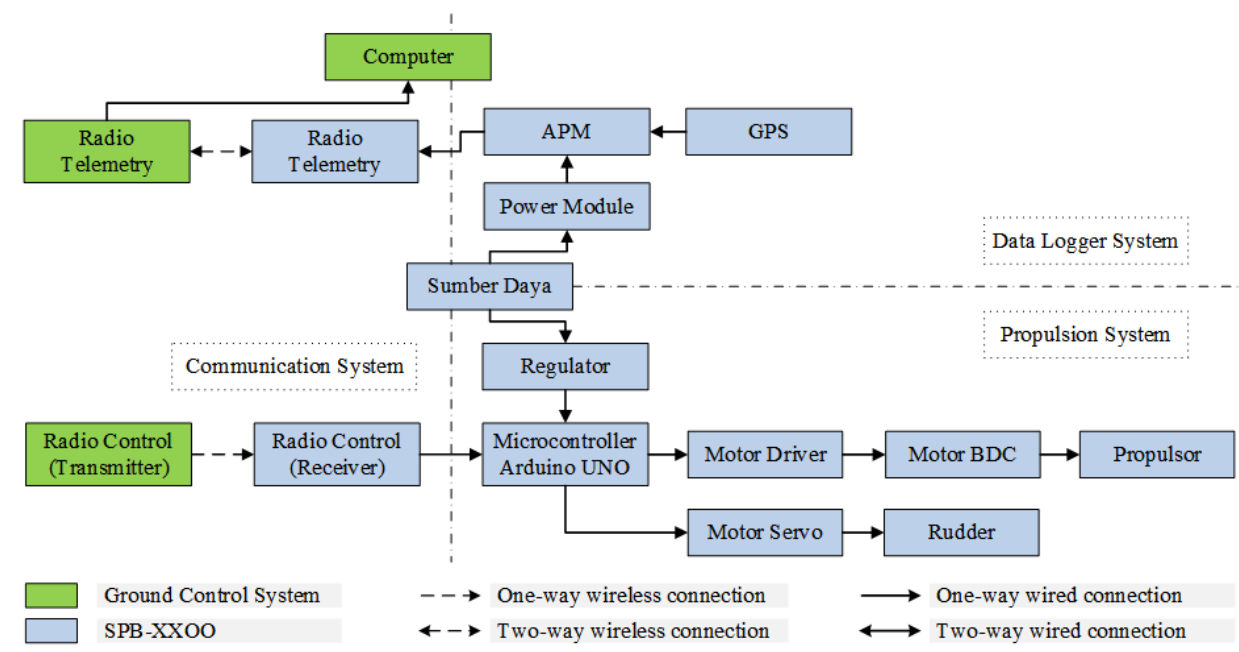

FIGURE 5 General framework of location, category and types of communication for each component of the instrumentation system.

- Library and User Interface Program, used as a user interface that can "display" the position of the model during its movements on earth based on GPS coordinate data in real-time.

- Arduino Integrated Development Environment (IDE) provides a program for the motor servo to adjust the rudder angle and a program for the motor to adjust the model speed.

- Driver CP21X, as the data converter provided by GPS to be displayed to the user interface and activity controller of radio telemetry (ground) module.

In the SPB-XXOO model, components are grouped into two systems: the propulsion system and the data logger system. The developed propulsion system must propel the model to move at a constant speed and a certain rudder angle. This system should be complete first before the data logger the system is developed. Microcontroller Arduino UNO has the most crucial role in its function as the controller of the entire propulsion system's components. The connection of each component in this system is given in Figure 5 .

The data logger system has a goal to record all of the model movement characteristics, including the coordinate position (longitude, latitude, and altitude), attitude (heave, surge, sway, pitch, roll, and yaw), direction, speed, 6 DoF movements, and many others. GPS is the most critical component in this system because its function is to determine the coordinate data position of the model based on its distance to several satellites. Its accuracy is crucial because it affects the accuracy of the result. The overall connection of components in the GPS data logger system shown in Figure 5

\section{3 | Experimental Scenario}

This experiment was conducted at Danau 8 ITS. The time chosen is between 7-10 a.m. or 3-5 p.m., because the blowing wind at that time is prolonged, so it almost does not cause any surface waves ${ }^{3}$. Wind and waves may create an external force to the model that has an impact on the accuracy of the experimental results. The wind also causes inaccuracies in the results of data logged by GPS. The experimental acquisition scenario was carried out, as shown in Figure 6 A total of 6 experiments were conducted. Each experiment has different specifications of the rudder model and rudder angle. 


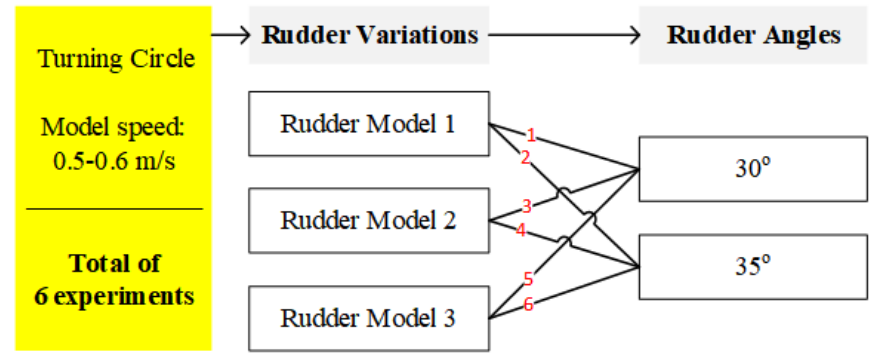

FIGURE 6 Data acquisition scenario.

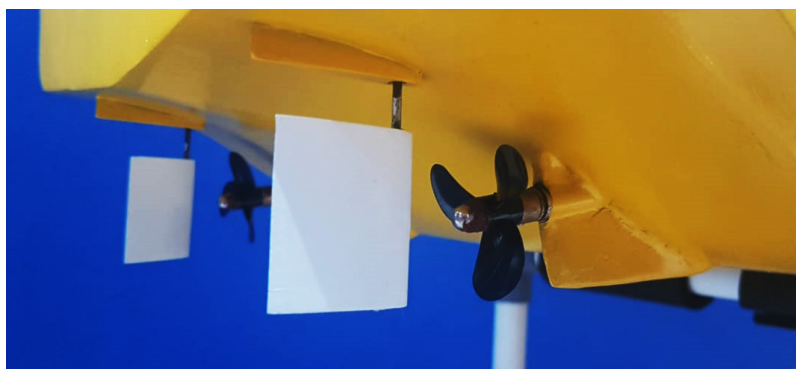

FIGURE 7 The rudder-model-1.

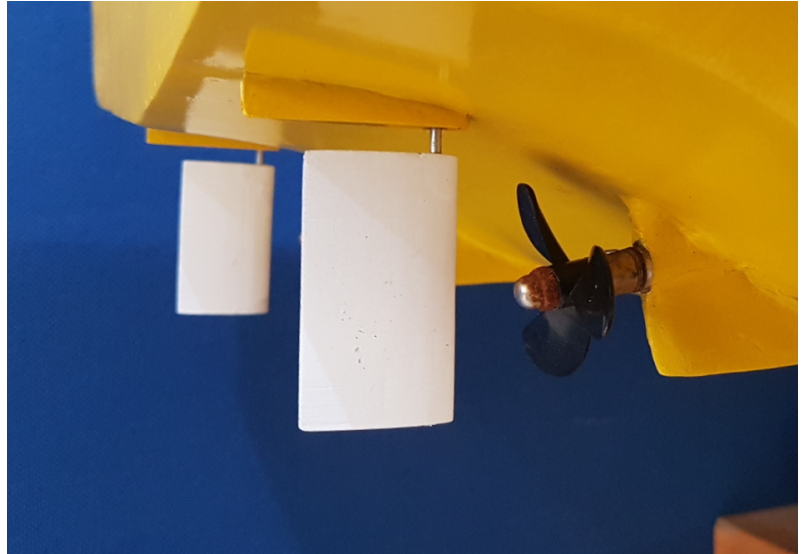

FIGURE 8 The rudder-model-2.

TABLE 3 Rudder dimension of SPB-XXOO model.

\begin{tabular}{lcccc}
\hline Rudder Model & Spam $(\mathbf{m m})$ & Chord $(\mathbf{m m})$ & Aspect Ratio & Area $\left(\mathrm{mm}^{2}\right)$ \\
\hline Model-rudder-1 & 37.93 & 34.48 & 1.10 & 1308 \\
Model-rudder-2 & 46.45 & 28.16 & 1.65 & 1308 \\
Model-rudder-3 & 53.68 & 24.37 & 2.20 & 1308 \\
\hline
\end{tabular}

\section{4 | Rudder Model}

The design process of rudders is done by varying the original rudder of SPUB into two others with the same rudder area and foil type. The length of the chord (c) and span (s) of the SPUB's rudder is 3 meters and 3.3 meters, respectively, and the aspect ratio is 1.1 . This original rudder then made into a 1:87 scale model called the rudder-model- 1 .

Based on the dimension of the rudder-model-1, variations of the rudder models 2 and 3 are made with a larger aspect ratio. This means that the rudder-model-2 would have a longer span and shorter chord than the rudder-model-1, as well as for the ruddermodel-3 to rudder-model-2. The dimensions of the model rudder are limited to the design aspects. The minimum thickness of the rudder foil is $2 \mathrm{~mm}$. Based on these calculations, the size of each rudder model is given in Table 3 . The most significant aspect ratio (Spam/Chord) of the three rudder models is 2.20, twice greater than the original model.

Based on the dimension given in Table 3 the three-dimensional rudder model is made using 3D modeler software. These three rudder models are designed to be installed into the SPB-XXOO model. The process of fabricating rudder models is done by a $3 \mathrm{D}$ printing machine to make the results more accurate. Figure 78 and 9 show the three rudder models installed on the SPB-XXOO model. 


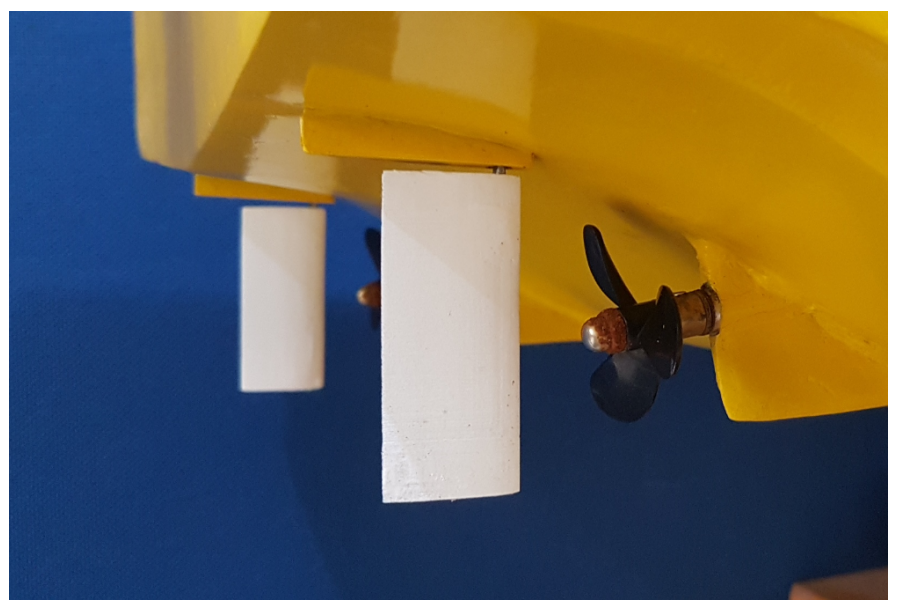

FIGURE 9 The User interface for coordinate distance calculations.

\section{5 | Process of Data Acquisition with GPS}

The experiment begins by propelling the model at a constant speed into the middle of Danau 8 ITS, then conducting a turning circle maneuver. During this process, the GPS records the data by receiving signals that contain a lot of information from the satellite. Using the "triangulation" calculation, GPS calculates its location (SPB-XXOO model) by comparing the time signal sent from the satellite with the time signal received in the GPS receiver. From that information, the GPS then performs an internal calculation to get the distance of the GPS module towards satellite location. By knowing the location of several satellites simultaneously, the distance calculation can be done, and the model coordinate position can be determined. The GPS must capture at least four or more satellite signals to get coordinates in 3D (latitude, longitude, and altitude).

At the same time, Ardupilot Mega (APM) received data from GPS that contain model maneuver data, then converted it into another format that could be displayed on the user interface. APM is also equipped with a gyroscope to conduct internal measurements in the form of attitude (heave, surge, sway, pitch, roll, and yaw), the direction of the model, and others. All data from the APM then sent to the computer by radio telemetry (air) to the radio telemetry (ground) via a wireless connection. The user interfaces process all data and then displayed in the user interface in the form of real-time graphical data. The data is stored in the user interface software library to be used as raw data in this study. Figure 5 shows the communication scheme between components in this data logger system.

\section{3 | RESULTS AND DISCUSSION}

\section{1 | The Data Processing and Results}

Based on the results of the experiment, a total of 171 experimental characteristic data were obtained for each experiment that had been carried out. Not all data is used in this study, but only coordinate data: longitude and latitude coordinates.

The first step that must be done to get the graph of SPB-XXOO model maneuver performance is to eliminate the unnecessary data of ship movements (longitude and latitude coordinate data). The experiment of turning circles starts from a straight motion at a constant rate, then the rudder is deflected at maximum speed to the angle $\delta$ (turning rudder) and stays at that angle until the ship has made a turning circle at least $540^{\circ}$ [10 . After the main data from each experiment are obtained, the next step is to create a graph of model maneuvering movement using computational and visualization software. The graphical data of the SPB-XXOO model maneuvering for every experiment in this study are given in Figure 10 to Figure 15

In this study, the vincenty formula method is used to calculate the tactical diameter. The application of this method is shown in Figure 16 The program interface is designed using graphical user interface software of numerical computing programs and computer programming languages based on the algorithm of calculating the distance of the coordinates that is available in that 


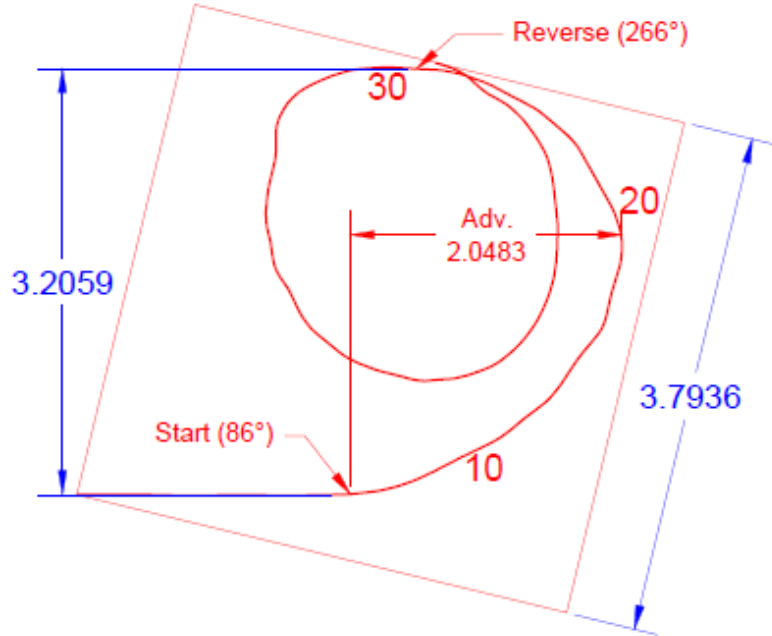

FIGURE 10 Turning diameter assessment of experiment-1.

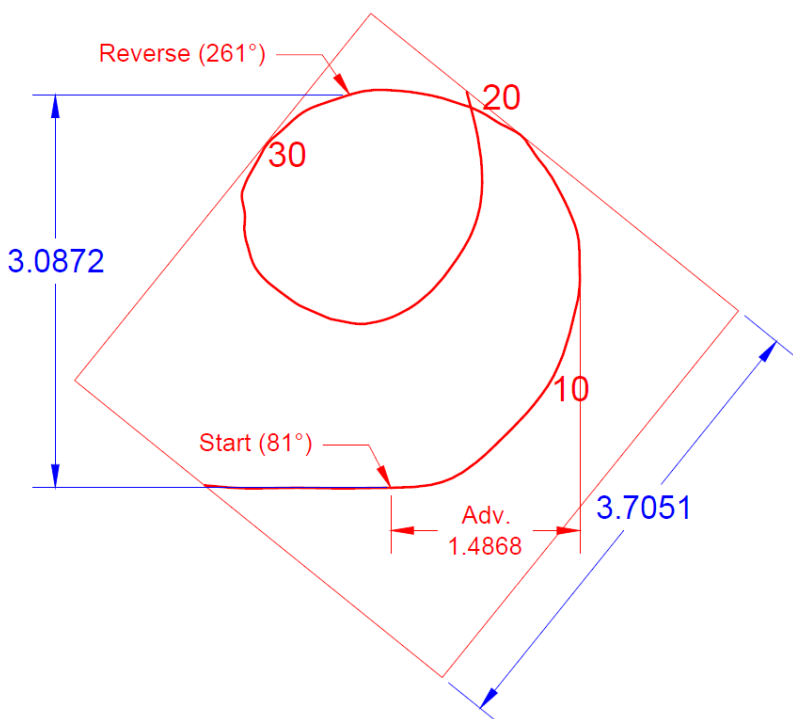

FIGURE 12 Turning diameter assessment of experiment-3.

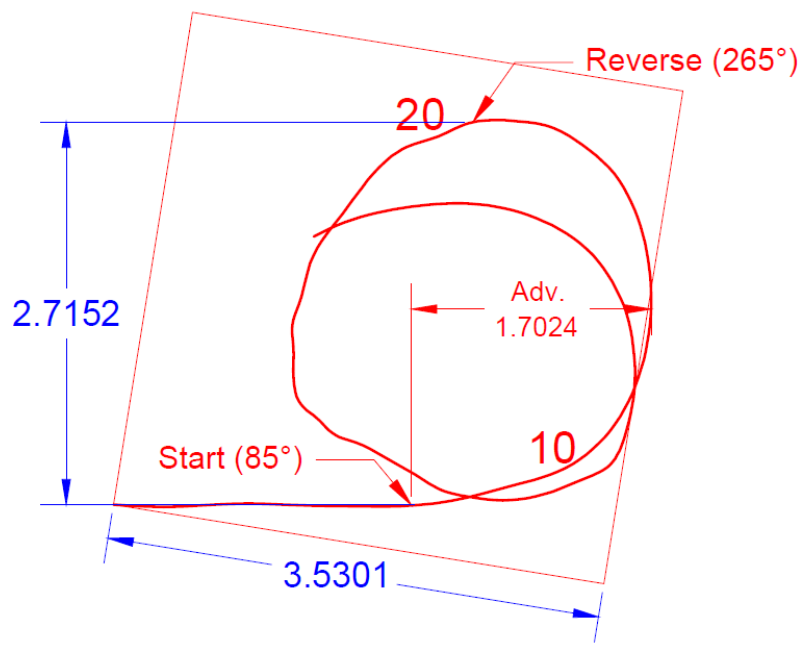

FIGURE 11 Turning diameter assessment of experiment-2.

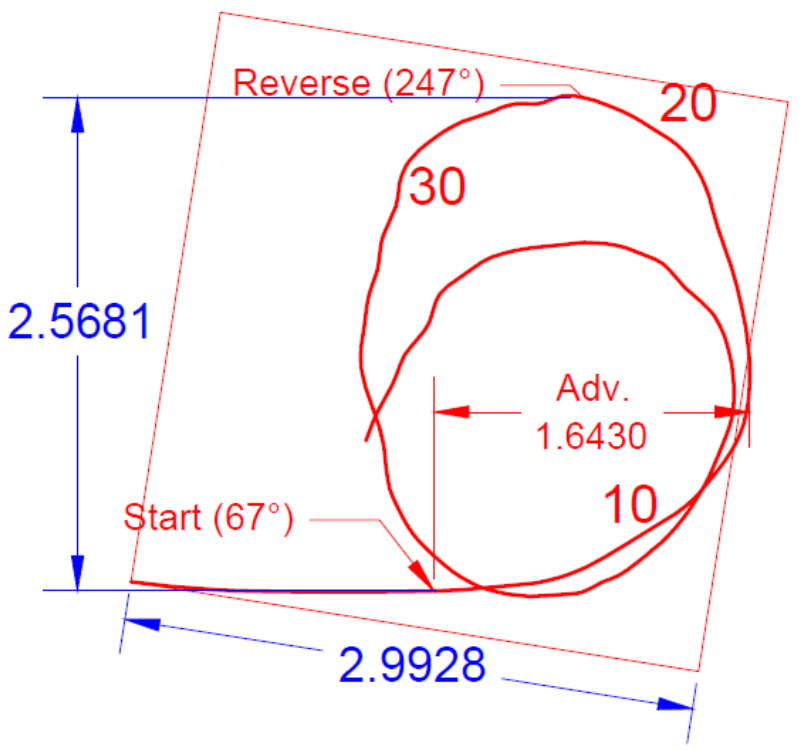

FIGURE 13 Turning diameter assessment of experiment-4.

software. To operate the software, the method is to enter the start coordinate value, and the second coordinate value (reverse heading), then the distance between the two coordinates can be obtained.

The coordinate of longitude and the latitude data captured by the GPS module are saved in the "Longitude-Latitude" coordinate system. To simplify the analysis process, the raw coordinate system is converted into a Universal Transverse Mercator (UTM) coordinate system. Not all coordinates are changed, but only the farthest distance between coordinates in one axis is converted. In experiment 1 , for example, the farthest distance is on the Y-axis. The two most distant points in the longitude coordinates are $-7.287082000^{\circ}$ and $-7.287116300^{\circ}$. These two coordinates are then converted into the UTM coordinate system. The conversion process is done with an online converter device on the internet. This conversion result given in Figure 17 shows that the farthest distance of the Y-axis is 3.794 meters. This distance is used as a reference for the finishing process, in the form of adding image captions. 


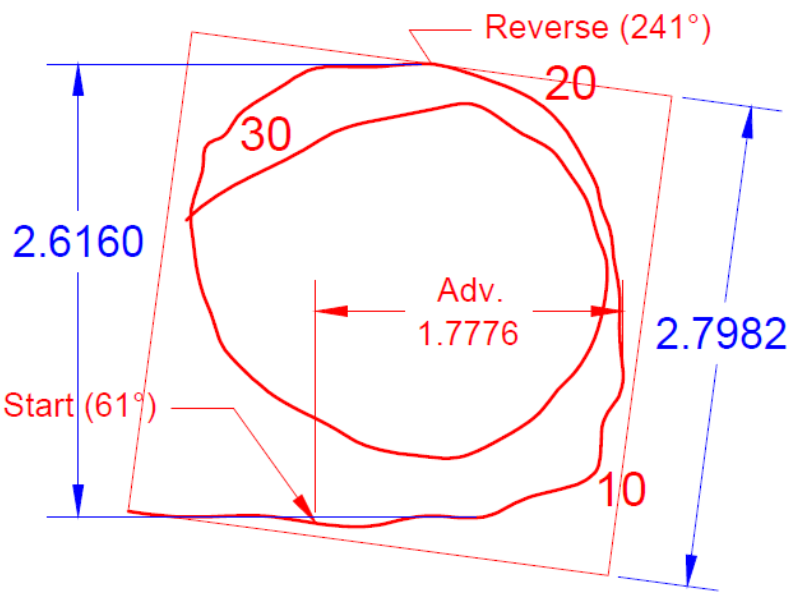

FIGURE 14 Turning diameter assessment of experiment-5.

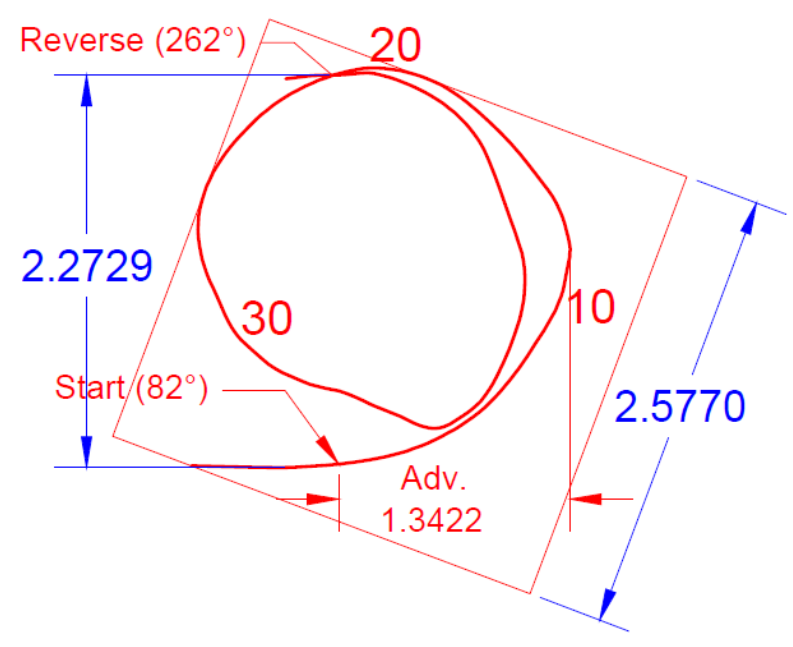

FIGURE 15 Turning diameter assessment of experiment-6.

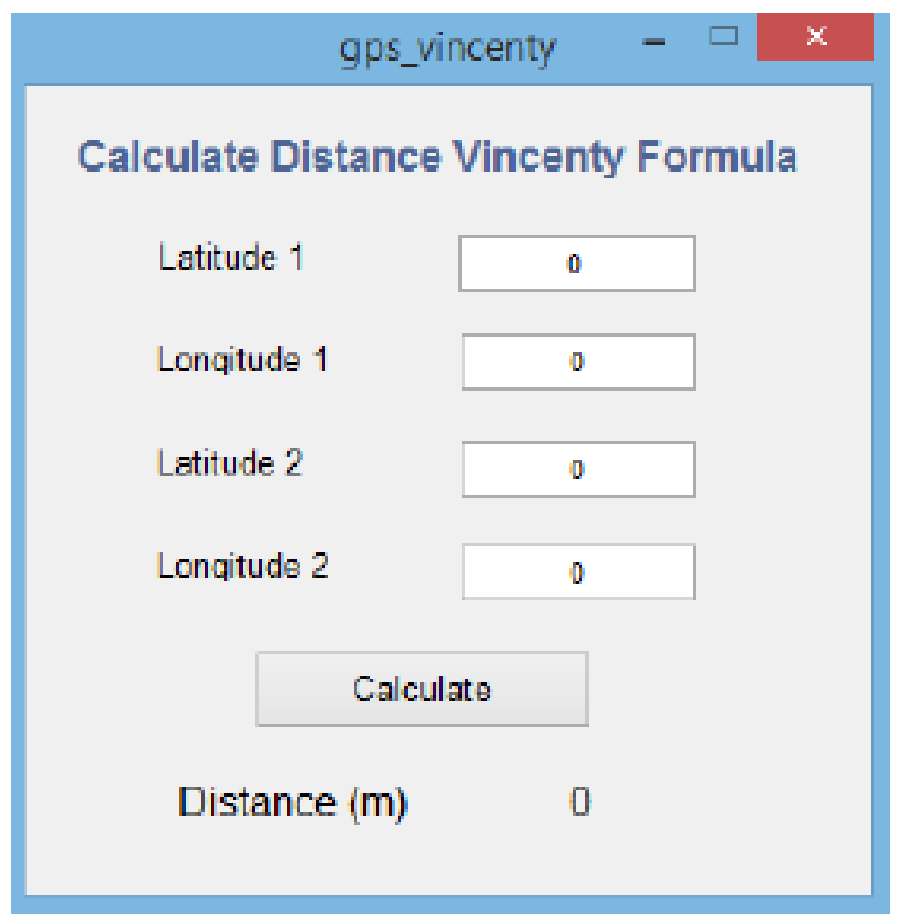

FIGURE 16 User interface for coordinate distance calculations.

\subsection{Analysis of Experiment Results}

Assessment of the rudder model performance is done to achieve the goal of stage-2, which is to analyze the effect of the rudder model on maneuver performance. Each rudder model will give different results if it has various shapes, sizes, types of foil, location, and rudder number.

This assessment process is done by comparing the results of the analysis of the three rudder models. The rudder model that gives the "best" experiment results will be decided to be the best model. The "best" criteria intended are to produce the lowest turning maneuver value compared to the model length. The results obtained must also be compared with the IMO criteria. IMO though IMO Resolution MSC.137 (76), requires that the value of tactical diameter at maximum rudder angle of $35^{\circ}$ is less 


\section{RUDDER 1 - 20 DEGREE}

\begin{tabular}{|c|c|c|c|c|}
\hline \multicolumn{5}{|c|}{ \#Longitude-Latitude Coordinate System } \\
\hline No & Parameter & Longitude (X) & Latitude (Y) & Note \\
\hline 2 & Min & 112.796068000 & -7.287116300 & - \\
\hline \multicolumn{5}{|c|}{ \# UTM Coordinate System } \\
\hline No & $\mathrm{X}$ & $\mathrm{Y}$ & Multiplication to the right & Multiplication to the left \\
\hline 1 & 698285.485325407 & 9194120.717948650 & $6.42012 \mathrm{E}+12$ & $6.42012 \mathrm{E}+12$ \\
\hline 1 & 698285.485325407 & 9194120.717948650 & 0 & 0 \\
\hline \multirow[t]{4}{*}{$\Sigma$} & & & $1.28402 \mathrm{E}+13$ & $1.28402 \mathrm{E}+13$ \\
\hline & & Total Area & 0 & $\mathrm{~m}^{2}$ \\
\hline & & Distance on $X$ axis & 0.015088928 & $\mathrm{~m}$ \\
\hline & & Distance on $Y$ axis & 3.793609079 & $\mathrm{~m}$ \\
\hline
\end{tabular}

FIGURE 17 Calculation of the farthest coordinate distance (experiment-1).

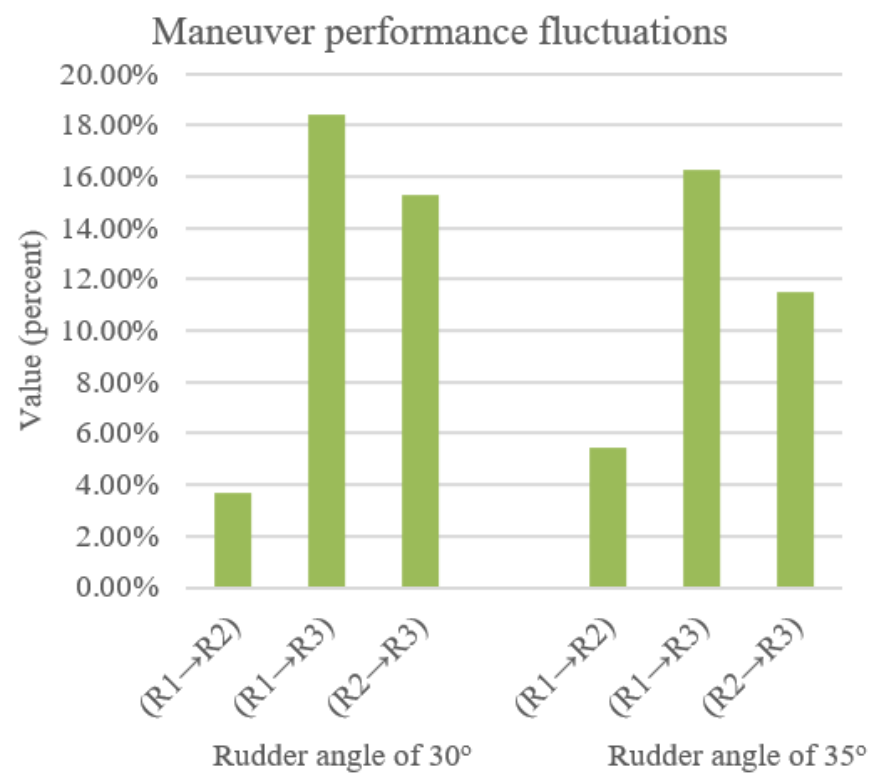

FIGURE 18 Fluctuation of maneuver performance.

than 5L ( $<5.0 \mathrm{~L}, \mathrm{~L}$ measured LPP). Based on these criteria, only experiments 2,4 , and 6 have the results compared with the IMO criteria. Other experiments are not analyzed because they have different rudder angles. The tactical diameter value and its assessment results against IMO criteria are given in Table 4

To find out the performance of the rudder model, it is necessary to group the experimental results based on the rudder angle. This is intended to provide a fluctuating percentage (increase/decrease) of maneuver performance based on rudder model replacement. After that, the calculation of fluctuations in maneuver performance is carried out. The results of this calculation are given in Table 5 and Figure 18 Positive values in the table indicate that there is still an increase in maneuver performance, while negative values indicate otherwise. Notation $(\mathrm{R} 1 \rightarrow \mathrm{R} 2)$ shows the rudder performance fluctuations from the rudder-model-1 to the rudder-model-2. 
TABLE 4 The value of tactical diameter and its assessment against IMO criteria.

\begin{tabular}{ccccc}
\hline No & Experiment & $\begin{array}{c}\text { Tactical } \\
\text { Diameter (TD) }\end{array}$ & $\begin{array}{c}\text { TD Compared } \\
\text { with } L_{P P}\end{array}$ & $\begin{array}{c}\text { Assessment } \\
\text { against IMO } \\
\text { criteria }\end{array}$ \\
\hline 1 & (R1-30) & 3.206 & 2.134 & - \\
2 & (R1-35) & 2.715 & 1.807 & Pass \\
3 & (R2-30) & 3.087 & 2.055 & - \\
4 & (R2-35) & 2.568 & 1.709 & Pass \\
5 & (R3-30) & 2.616 & 1.741 & - \\
6 & (R3-35) & 2.273 & 1.513 & Pass \\
\hline
\end{tabular}

TABLE 5 Tactical diameter of each experiments and its fluctuation based on rudder model replacements.

\begin{tabular}{|c|c|c|c|c|c|}
\hline Experiments & $\begin{array}{c}\text { Tactical } \\
\text { Diameter } \\
\text { (meter) }\end{array}$ & $\begin{array}{c}\text { Tactical } \\
\text { Diameter } \\
\text { Against LPP }\end{array}$ & No & $\begin{array}{l}\text { Rudder Model } \\
\text { Changes }\end{array}$ & $\begin{array}{c}\text { Maneuver } \\
\text { Performance } \\
\text { Fluctuation }\end{array}$ \\
\hline \multicolumn{6}{|c|}{ Group of 30 degree } \\
\hline $1(\mathrm{R} 1-30)$ & 3.206 & 2.134 & 4 & $(\mathrm{R} 1 \rightarrow \mathrm{R} 2)$ & $3.70 \%$ \\
\hline $3(\mathrm{R} 2-30)$ & 3.087 & 2.055 & 5 & $(\mathrm{R} 2 \rightarrow \mathrm{R} 3)$ & $15.26 \%$ \\
\hline $5(\mathrm{R} 3-30)$ & 2.616 & 1.741 & 6 & $(\mathrm{R} 1 \rightarrow \mathrm{R} 3)$ & $18.40 \%$ \\
\hline \multicolumn{6}{|c|}{ Group of 35 degree } \\
\hline $2(\mathrm{R} 1-35)$ & 2.715 & 1.807 & 7 & $(\mathrm{R} 1 \rightarrow \mathrm{R} 2)$ & $5.42 \%$ \\
\hline 4 (R2-35) & 2.568 & 1.709 & 8 & $(\mathrm{R} 2 \rightarrow \mathrm{R} 3)$ & $11.49 \%$ \\
\hline 6 (R3-35) & 2.273 & 1.513 & 9 & $(\mathrm{R} 1 \rightarrow \mathrm{R} 3)$ & $16.29 \%$ \\
\hline
\end{tabular}

Table 5 shows the tactical diameter value against the length of the model for each experiment, also the fluctuation of maneuver performance based on rudder model changes. The calculated fluctuations are the performance of the model 1 to the ruddermodel-2 (R1 $\rightarrow$ R2), the rudder-model-2 to the rudder-model-3 $(\mathrm{R} 2 \rightarrow \mathrm{R} 3)$, and the rudder-model-1 to the rudder-model-3 (R1 $\rightarrow$ R3). All three show improved maneuver performance. All experimental data shows positive values. This means that the increase in the aspect ratio of the rudder has a positive impact on ship maneuvering performance. The average increase in the performance of the SPB-XXOO model maneuver from the rudder-model-1 to the rudder-model-2 (R1 $\rightarrow \mathrm{R} 2)$ is $4.560 \%$, from the rudder-model- 1 to the rudder-model-3 $(\mathrm{R} 1 \rightarrow \mathrm{R} 3$ ) is $17.345 \%$, and from the rudder-model-2 to the rudder-model-3 (R1 $\rightarrow$ $\mathrm{R} 2$ ) is $13.379 \%$.

Figure 18 shows that the two rudder angles have different fluctuations, even though they use the same rudder model. The group of rudder angle $35^{\circ}$ shows more consistent fluctuations compared to the group of rudder angle $30^{\circ}$. The difference between both groups is not too big, but it causes inconsistency in the experimental results. Many factors can cause this error, including:

- External factors, winds, and waves that blowing anytime, which may cause the SPB-XXOO model to receive different external forces for each experiment. This will make the error value varied for each experiment;

- External factors, wind, which interfere with the satellite signal capture process by the GPS module. Different gusts of wind at any time will also cause error varied for each experiment;

- The internal error of the data logger component in capturing SPB-XXOO model coordinate data because of the limitation on the calculating process, data transfer speed, delay, and many more;

- Differences in the number of active satellites in each experiment. The more satellite signals captured, the higher the accuracy of the SPB-XXOO model coordinate location; or

- Errors of researchers in the process of analysis/calculation.

\section{4 | CONCLUSION}

Several results show the same trend towards operating conditions An experimental design has been made with four main components in the experimental process, namely operators and computers in ground control systems and SPB-XXOO models and 
data loggers on Lake 8 ITS. All of these components are integrated to carry out the entire experimental process starting from propelling the model to conduct the turning circle movements, the process of data logging, and the process of transferring all model movement information/data to the computer (server).

In this study, three rudder models are used as a variant in the study. The rudder-model-1 represents the original form of the SPUB rudder with the same series of foil and the same aspect ratio. Rudder models 2 and 3 are improvements of the ruddermodel-1 with a higher aspect ratio, but still the same foil series and area of the rudder. The aspect ratio (span/chord) of the three rudder models are $1.10 ; 1.65$; and 2.20 , respectively.

Based on the results of the experimental analysis on stage 2 given in the form of descriptions, figures, and tables, it can be concluded that a rudder with a high aspect ratio will perform a better maneuvering performance compared to the rudder with a low aspect ratio even with the same area. From this study, it can be determined that the rudder-model-3 was (aspect ratio of 2.2) chosen to be the rudder model with the best maneuver criteria for the movement of turning circles compared to the model rudder 1 and 2 (aspect ratio of 1.1 and 1.65).

\section{References}

1. Prayoga NB, Aryawan WD. Desain Self-Propelled Oil Barge (SPOB) untuk distribusi crude oil di Kabupaten Sorong, Papua Barat. Jurnal Teknik ITS 2016;5(1):G19-G24.

2. Shi CJ, Zhao D, Peng J, Shen C. Identification of Ship Maneuvering Model Using Extended Kalman Filters. International Journal on Marine Navigation and Safety Sea Transportation 2009;3(1):105-110. http://www.transnav.eu/

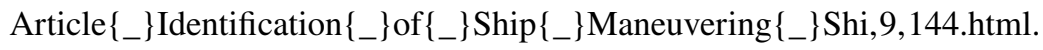

3. Akbar R. Pemodelan Kapal Perang Kelas Sigma Extended Skala 3 Meter Berbasis Eksperimen. PhD thesis, Institut Teknologi Sepuluh Nopember; 2014.

4. Im N, Seo JH. Ship Manoeuvring Performance Experiments Using a Free Running Model Ship. International Journal on Marine Navigation and Safety of Sea Transportation 2010;4(1):29-33.

5. National Aeronautics and Space Administration (NASA), Hall N, editor, Geometry Definitions. National Aeronautics and Space Administration (NASA); 2018. https://www.grc.nasa.gov/www/k-12/airplane/geom.html

6. Anggara S. Studi Komperatif Performa Hidrodinamik Kapal Bertipe Shallow Draft Barge pada Kondisi Perairan Dangkal, Sedang dan Dalam. PhD thesis, Institut Teknologi Sepuluh Nopember; 2013.

7. Ahadyanti GM. Modifikasi Bentuk Lambung pada Shallow Draft Bulk Carrier untuk Menurunkan Konsumsi Bahan Bakar. PhD thesis, Institut Teknologi Sepuluh Nopember; 2014.

8. R Dahna. Analisis Alternatif Hull Form Self-Propelled Barge Untuk Meningkatkan Performa Hidrodinamika. PhD thesis, Institut Teknologi Sepuluh Nopember; 2018.

9. Group IQ, Committee I, editor, Recommended Procedures and Guidelines: Resistance Test, Rev 3. ITTC; 2011.

10. Fossen TI. Guidance and Control of Ocean Vehicles. 1 ed. New York: Wiley; 1994.

How to cite this article: Hutama R.A., Aryawan W.D., Sugita E.D. (2020), Ship Maneuverability Experiments on Open Water with Rudder Model Variations: Case Study of SPB-XXOO, IPTEK The Journal of Technology and Science, 31(1):54-66. 